\title{
EREBEA
}

Revista de Humanidades

y Ciencias Sociales

Núm. 5 (2015), pp. 215-241

ISSN: 0214-0691

\section{UN PARADIGMA DE PRÁCTICAS RELIGIOSAS EN TIERRAS DE Huelva durante la EdAd Moderna: El Rosario de la AURORA Y SUS COPLAS}

\author{
Carlos José Romero Mensaque \\ U.N.E.D. Sevilla
}

RESUMEN

Este artículo ofrece una panorámica general del fenómeno de los Rosarios públicos y las coplas de aurora en tierras onubenses durante el siglo XVIII, concretamente en varias poblaciones representativas. El Rosario público o callejero constituye un paradigma de la religiosidad moderna espańola y crea una amplia tipología de cortejos con sus faroles y estandartes y, sobre todo, las coplas de aurora, cuyas letras hemos recuperado en este artículo.

Palabras Clave

Rosario; Rosarios públicos; Coplas de aurora; Auroros; Campanilleros.

Fecha de recepción: 18 de mayo de 2015

Fecha de aceptación: 30 de octubre de 2015

\section{Abstract}

This article provides an overview of the phenomenon of public rosaries and the coplas (songs) of dawn in Huelva lands during the eighteenth century, in particular in several representative populations. The public or street rosary is a paradigm of modern Spanish religion, and it creates a wide typology of processions with lanterns and banners. Most noteworthy of all are the coplas of dawn, whose lyrics we have recovered in this article.

KeYWORDS

Rosary - public rosaries; coplas (songs) of dawn; "Auroros"; "Campanilleros". 



\section{INTRODUCCIÓN. GÉNESIS DE LA DEVOCIÓN DEL ROSARIO Y PRINCIPALES ETAPAS}

HISTÓRICAS

La génesis del Rosario coincide con la prerreforma católica y se sitúa primeramente en la órbita benedictina y cartuja (siglos XIII al XV) para conformarse definitivamente en el seno de la Orden de Predicadores con la fundación de la Cofradía del Rosario (Alano de la Roca y Jacobo Sprenger, 1475), consolidándose tras Trento con el acontecimiento de Lepanto (1571), todo un hito reivindicativo de la Iglesia que en España alcanza una significación muy especial. El Rosario se imbrica en una pastoral que rebasa el patrocinio jurídico de los Dominicos y se fomenta por los ordinarios diocesanos en todas las parroquias españolas con la fundación de las cofradías y se convierte en práctica devocional en las misiones. Esta universalización será el detonante de la auténtica "explosión rosariana" que supone el fenómeno de los Rosarios públicos que, surgidos a fines del siglo XVII en Sevilla (1690. Fray Pedro de Santa María y Ulloa), será el paradigma del Rosario por excelencia hasta nuestros días en toda la geografía peninsular e insular. ${ }^{1}$

1 Es imprescindible como fuente documental Acta Sanctae Sedis necnon Magistrorum et Capitulorum Generalium Sacri Ordinis Praedicatorum pro Societate SS. Rosarii, coordinada por Fray José Marí Larroca, 2 v., cinco partes, Lyon 1991-92. Quizá la mejor síntesis histórico-teológica sea la de André DUVAL, "Rosaire", en Dictionnaire de Spiritualité, Ascétique et Mistique, tomo 13, 1988, págs. 937-980, que actualizó y sistematizó otra anterior de Maxime Gorce, "Rosaire" en Dictionnaire de Théologie Catholique 13 (1937), col. 2902-2011. De este autor, también Le Rosaire et ses antécédents historiques d'après le manuscrite 12483, fond français de la Bibliothèque National, Paris, A.Picard, 1931. El tratadista clásico en lengua española es el padre Luis G. Alonso Getino, Origen del Rosario y leyendas castellanas del siglo XIII sobre Santo Domingo de Guzmán, Madrid, Vergara, 1925. Otros autores españoles, ya contemporáneos, son Lorenzo Galmés Más, "El Rosario en la Historia”, en Herminio de Paz Castaño y C. Romero Mensaque (Coords.) Congreso Internacional del Rosario. Actas, Sevilla, 2004, pp. 37-47, Juan Carlos Pacheco Ceballos, "La devoción del Rosario y la Orden de Predicadores", en Herminio de Paz Castańo y C. Romero Mensaque (Coords.), Congreso Internacional del Rosario. Actas, Sevilla, 2004, pp. 301-310 y la elaborada síntesis de Fermín Labarga García "La devoción del rosario. Datos para la historia", en Archivo Dominicano XXIV, 2003, pp. 225-277. Como se puede observar, en 2004 se celebró en Sevilla un Congreso Internacional del Rosario, coordinado por la Provincia Bética de la Orden de Predicadores, que fue un importante evento dominicano en el estudio histórico y acción pastoral del rezo. El año anterior se celebró otro en León, pero de ámbitos más reducidos: Miguel Iribertegui Eraso (dir), El Rosario de María. IV Congreso del Rosario, León, 2003. En el ámbito español, cabe indicar tres avances de la reciente tesis doctoral inédita de Carlos Romero Mensaque. 


\subsection{Primer momento (1475-1563): el kerigma}

La génesis y primer desarrollo en Europa durante el último tercio del siglo XV y primera mitad del XVI en torno a la "devotio moderna" merced a la Orden de Predicadores con la aparición de las primeras cofradías y su progresiva llegada a España donde arraiga de una manera muy significativa y en parte original. Cuando Fray Alano de la Roca, un dominico observante bretón, funda una confraternidad del Psalterio de la Virgen en 1470 en Douai (Provincia dominica de Holanda), se culmina un dilatado proceso de conformación del rezo avemariano, cuyos precedentes se remontan a los siglos XII y XIII. Pero el Rosario o Psalterio de la Virgen no puede conceptuarse sólo como una devoción popular, sino también como un elemento más del nuevo concepto de "devotio moderna" imbuido en la pre-Reforma católica y un distintivo de las comunidades o congregaciones dominicas observantes.

\subsection{Segundo momento (1563-1690): la universalización}

El segundo gran hito en la devoción rosariana, otro auténtico acontecimiento en su historia, lo constituirá la victoria de la Armada cristiana en el golfo de Lepanto frente al Turco (7 de octubre de 1571), que fue atribuida por el papa Pío V, dominico, a la intercesión de la Virgen del Rosario y a la coincidencia de que el mismo día la Cofradía establecida en Roma (Minerva) había salido con sus cofrades en procesión por las calles alabando a la Virgen. Posteriormente, en 1573, el Papa Gregorio XIII expidió un Breve estableciendo el primer domingo de octubre como festividad de la Virgen del Rosario a celebrar en aquellos lugares donde hubiera altar o capilla dedicada a esta advocación. Este evento hay que relacionarlo necesariamente con los esquemas pastorales del Concilio de Trento y la recomendación de ordenar y controlar las prácticas devocionales. En este sentido el Rosario no sólo continuará con su difusión, sino que se revalorizará por parte de la jerarquía como un medio eficaz de normalización de la religiosidad popular. A partir de Lepanto la devoción adquiere un carácter universal y traspasa los ámbitos dominicanos, propagándose las cofradías a las distintas parroquias

\footnotetext{
Un paradigma de la religiosidad popular en España durante la época moderna: La devoción del Rosario y sus cofradías (Murcia, 2015) y los artículos "Los comienzos del fenómeno rosariano en la España Moderna. La etapa fundacional (siglos XV y XVI)", en Hispania Sacra, Extra 2, 2014, "La universalización de la devoción del Rosario y sus cofradías en España. De Trento a Lepanto", Angelicum, vol. 90, 2013, pp. 217-246. y "El fenómeno de los rosarios públicos en Espańa durante la época moderna. Estado actual de la cuestión”, Revista de Humanidades, no 19, 2012, pp. $87-$ 115. Vid. También un interesante artículo de Vito T. Gómez sobre los documentos pontificios referentes a España en el siglo XVI: "El Rosario en España y América a través de bulas pontificias del siglo XVI”, en Teología Espiritual, XLVII (2003), pp. 223-247. Una fuente muy importante para el estudio del Rosario en la nación es la revista Santísimo Rosario. Sobre la cuestión en Andalucía, vid. El ya citado Romero Mensaque: "El Rosario y sus cofradías en Andalucía. Una aproximación histórica”, en Hispania Sacra, 126, Madrid, CSIC, pp. 621-659.
} 
en que padres promotores de la orden, a petición de los ordinarios diocesanos, las erigían formalmente en nombre del Maestro General de la Orden, pues el mencionado Pío $\mathrm{V}$ había reservado esta exclusiva a los frailes predicadores.

\subsection{Tercer momento (1690-1800): la popularización}

La tercera época deriva de esta universalización lepantina o trentina, que será el detonante de la auténtica "explosión rosariana" que supone el fenómeno de los Rosarios públicos que, surgidos a fines del siglo XVII en Sevilla, aunque con precedentes claros en Italia y colonias americanas, será el paradigma del Rosario por excelencia hasta nuestros días en toda la geografía peninsular e insular. Esta evolución nos indica asimismo cómo el rezo, la devoción y la Cofradía evolucionan desde un ámbito exclusivamente elitista, a una dimensión más "oficial" o institucional (Trento) hasta una clara y profundamente popular. La Orden de Predicadores ha otorgado al Rosario su seña de identidad, y en las dos primeras etapas creó en torno a sus conventos un interesantísimo asociacionismo laico. Posteriormente, el clero secular y otras órdenes religiosas, como capuchinos, jesuitas, franciscanos o mercedarios, encauzaron el fenómeno hasta que ya en el siglo XVIII asistimos a una autonomía del laicado, que, sin obviar la tutela clerical, se hace consciente de su protagonismo en la religiosidad que él mismo vive, como en una expresión barroca y popular de la "devotio moderna".

Tras una etapa de apogeo en el siglo XVIII, se inicia un periodo crítico de la religiosidad popular, que tiende a abandonar la esfera de lo público (fin del régimen de cristiandad barroca) y refugiarse en los templos. La devoción rosariana se va a centrar en el culto a la imagen titular en el mes de octubre, con solemne función y procesión, experimentándose un renacimiento de la misma en la segunda mitad del siglo XIX y primera del XX junto a la tradición del Rosario de la Aurora y los coros de campanilleros, que han dejado un rico patrimonio de coplas.

\section{El Rosario PÚblico: GÉNESIS Y PRIMER DESARROLLO HISTÓRICO}

En los años finales del siglo XVII se constata el indiscutible influjo carismático de un fraile excepcional que, en sólo tres años de labor apostólica (1687-1690) en la capital hispalense, logró concitar en torno al real convento de San Pablo grandes multitudes de fieles. No era sólo la predicación o el rezo meditado del Rosario tres veces al día, sino toda una labor de asistencia y dirección espiritual que generó un núcleo de laicos afectos a su persona y al carisma de Santo Domingo. Me refiero, claro está, a Fray Pedro de Santa María y Ulloa, más conocido como el apóstol del Rosario ${ }^{2}$.

2 Sobre la figura y obra apostólica del padre Ulloa, vid. el prólogo de la obra autógrafa de este fraile Arco iris de paz, Barcelona, 1765 y que redactó fray Diego de la Llana (pp. 7-107). Igualmente la breve biografía de Aureliano Pardo Villar: "Escritores místicos gallegos: el venerable Fray Pedro de Santa María de Ulloa", en Cuadernos de Estudios Gallegos, 1950, n 15. Más recientemente, 
Su figura es paradigma de una etapa de clara revitalización de la Orden y su pastoral en el marco de la compleja religiosidad sevillana, tanto la oficial como la popular, consiguiendo un dominicanismo efectivo más allá incluso de la propia pastoral en sí y donde el convento de San Pablo se va a convertir en centro primordial de referencia.

El primer Rosario público reconocido como tal y con esa formal denominación en Sevilla, sin insignia alguna, fue el de los feligreses de la parroquia de San Bartolomé y en torno a la imagen de Nuestra Señora de la Alegría, la patrona del barrio y que contaba con una hermandad, que posteriormente se encargaría de la organización formal de los Rosarios. La salida- el 17 de junio de 1690coincidió con la celebración de los solemnes funerales por el padre Ulloa en San Pablo. En esta parroquia había predicado el dominico con gran éxito la Cuaresma anterior y, al igual que en su convento, creó una dinámica misional de rezar el Rosario todos los días a la aurora, mediodía y prima noche que se mantuvo tras su muerte y generó una nueva cotidianidad con los Rosarios públicos. ${ }^{3}$ No obstante esto, he encontrado copia de un acuerdo suscrito entre el Colegio Seminario de San Telmo y la Venerable Orden Tercera de Santo Domingo de San Pablo en 1725 por el que estipula que todos los niños del Colegio tomen el escapulario y profesen en esa Orden Tercera. Era el colofón formal a una vinculación entre estas dos corporaciones a raíz de que los niños hicieran estación al convento de San Pablo en su procesión habitual del Rosario desde la época del padre Ulloa. ${ }^{4}$ Encontramos, pues, otra vinculación directa entre las predicaciones de Ulloa y los primeros cortejos. Parece incluso inferirse que pudiera haber sido en vida de Ulloa. Además, la Orden Tercera de San Pablo fue la pionera de los cortejos del Rosario de Madrugada. Teniendo en cuenta que Ulloa fue, además, el reorganizador de la Tercera Orden en San Pablo, es decir, del laicado dominicano, podemos inferir el calado de esta figura carismática en la Orden.

He podido localizar en la Biblioteca de la Universidad de Barcelona un interesantísimo impreso sevillano "Modo de rezar el Rosario por la calle..." (Modo de rezar, s/a) que, aunque sin fecha, cabe deducir de su tenor que se

Antonio Larios Ramos "Pedro de Santa María Ulloa, apóstol del Rosario", en Herminio de Paz Castaño y Carlos Romero Mensaque (coords.), Congreso Internacional del Rosario. Actas: Sevilla, 2004, pp. 77-92.

3 Son varias fuentes coetáneas las que confirman la primacía de la parroquia de San Bartolomé y el vigor y entusiasmo de feligreses y cofrades en tono al rezo y a su común devoción a la Virgen de la Alegría, que era la imagen de referencia de este primer cortejo, así como la espontaneidad de unos cortejos en los que no figuraba insignia alguna salvo faroles o hachas encendidas.

4 Archivo de la parroquia de la Magdalena (Sevilla), Protocolo de la Hazienda de cassas, tributos y demás possesiones que al presente tiene y tuviese en adelante el Venerable Orden Tersero de la Milisia de Jessu-Christo nro bien, y Penitensia de nuestro gran padre y glorioso patriarca Sto. Domingo de Guzmán..., fol. 1-2. He consultado copia custodiada en el Archivo General de la Provincia Bética de la Orden de Predicadores. 
compone en los primeros momentos de los Rosarios. Se trata de un auténtico directorio para organizar estos primeros cortejos y, aunque está dirigido a los devotos del Rosario del Sagrario tiene una clara vocación universal para todos los de la ciudad. Lo primero que se detecta en su tenor es que la iniciativa acababa de empezar pues no se menciona en los cortejos ni la cruz ni ninguna insignia. El Rosario lo constituían los propios fieles con la tutela de un eclesiástico y lo que más interesaba era la organización del rezo.

Este dato nos confirma que se trata probablemente de la primera fijación por escrito del proceso de organización de los Rosarios públicos, por lo que puede afirmarse un primer modelo sevillano de estos cortejos, sin duda anterior al que en 1691 conformara con cruz y estandarte el capuchino Fray Pablo de Cádiz en la ciudad gaditana. El impreso establece un concepto del Rosario callejero como una procesión abierta a todo tipo de integrantes, incluso nińos acompañados de sus padres, de carácter claramente penitencial, donde los integrantes han de saber guardar en todo momento la seriedad y la compostura, estando muy atentos a la meditación de los Misterios que se consideran y al canto fervoroso de las avemarías a coros y las letanías. Es todo un esquema derivado de las misiones y que pretende ser ejemplificante.

Aparece pronto una primitiva división entre los cortejos de prima noche y los que salen al alba (posteriormente denominados de madrugada o aurora), a los que se da un realce especial al incorporar la celebración de la misa a su finalización, lo que integra la devoción con el sacramento, la religiosidad popular con la oficial. Este Rosario de la aurora tiene el preámbulo de los hermanos de la campanilla que avisan a los vecinos de la salida del Rosario y que va a crear una cotidianidad ordenada en las mañanas de los días festivos, especialmente para los trabajadores del campo, que de esta manera cumplían también el precepto dominical.

\section{El rosario de la aurora}

Nacido al mismo tiempo que el resto de las modalidades del Rosario público en la ciudad de Sevilla y más concretamente del convento dominico de San Pablo, el Rosario de la Aurora va a gozar de una identidad propia y de una enorme popularidad entre las gentes más humildes de nuestros pueblos y ciudades. El Arzobispo de Sevilla Jaime de Palafox y Cardona, a partir de 1690, fue un decidido impulsor de este uso devocional, estableciéndolo en la capital y fomentándolo en muchas localidades de la archidiócesis, imponiendo incluso su autoridad ante la negativa de determinados sectores del clero parroquial.

Tuvo desde el principio un cierto carácter marginal respecto de la religiosidad oficial, pues por cuestiones horarias no podía salir de las parroquias y había de hacerlo de oratorios o ermitas, algunas edificadas expresamente para este motivo. Esta circunstancia marcaba una cierta dualidad entre ambas sedes y ambas 
religiosidades y no poca competencia, lo que molestaba sobremanera al clero por cuanto estas congregaciones del Rosario recogía importantes limosnas en detrimento de las parroquias, donde normalmente estaban erigidas las cofradías dominicas o los cortejos vespertinos y nocturnos.

Esta procesión de la Aurora tenía una gran particularidad respecto a la de Prima Noche y es que, tras la recogida en su sede, los cofrades asistían a la misa denominada "de alba". Esto indica ya un signo de estabilidad en la congregación organizadora en cuanto a concurso de devotos y cofrades y, por ende, a ingresos económicos que permitiera sufragar los gastos procesionales y estipendio del capellán de misas. También supone un medio de comunión con la religiosidad oficial al favorecer la participación de los cofrades en la máxima expresión de la liturgia que es la eucaristía. Pero aún hay más. Estas misas de alba, que ahora fomentan estos Rosarios, suponía facilitar el cumplimiento eucarístico a los trabajadores del campo que comenzaban muy pronto su jornada laboral... y también a los pobres y marginados de la sociedad, que a veces no se atrevían por su indumentaria a participar en los cultos de iglesia.

En este sentido, el Rosario de la Aurora era considerado en general por la élite ilustrada del siglo XVIII un ejercicio útil y saludable y así se recoge en múltiples expedientes. La razón es que facilitaba el cumplimiento eucarístico dominical para los trabajadores del campo en la misa de alba, aparte de que constituía un excelente y puntual "despertador" para el horario laboral. Así se explicita en las Cartas de España de Blanco White ${ }^{1}$

"Existe en nuestros pueblos la antigua costumbre de despertar a los trabajadores antes del alba para que tengan tiempo suficiente de prepararse para sus labores, especialmente cuando han de ir a los sembrados, que con frecuencia están a seis u ocho millas de sus casas. Sólo la religión ha sido capaz de mantener esta costumbre. Desde tiempo inmemorial se ha establecido entre nosotros el Rosario, es decir, una procesión que sale antes del amanecer a cantar alabanzas a la Virgen Maria. Un hombre de buena voz, activo, sobrio y amigo de madrugar, bien sea pagado, bien preste sus servicios desinteresadamente, recorre las calles una hora antes del alba llamando a las puertas de los que quieren asistir al Rosario e invitando a todos a dejar el lecho y reunirse para alabar a la Madre de Dios. La invitación se hace en coplas breves cantadas con una melodía muy sencilla y acompañadas por el bello y variado sonido de una esquila, que va marcando el compás. Me ha gustado siempre mucho escuchar desde la cama el efecto de la esquila y la voz y no me ha gustado menos el coro completo de la procesión que viene después. El canto, algo monótono, armoniza admirablemente con la tranquilidad de la hora y, sin apartar completamente el suave y ligero sueño de la mañana, ahuyenta del alma las ideas de soledad y silencio 
susurrando la proximidad de la vida y la actividad que vuelven con el nuevo dia" ${ }^{5}$

El cortejo solía salir en torno a las tres o tres y media de la madrugada y la estación se prolongaba una hora $\mathrm{u}$ hora y media para que coincidiera el comienzo de la misa con las primeras luces del amanecer.

\section{LAS Coplas de los Rosarios de la AURora}

Hay en la archidiócesis hispalense una importante tradición de las coplas del Rosario de la Aurora, que se remontan a los años finales del siglo XVII, adquiriendo sus características más genuinas en los siglos XIX y primer tercio del XX, con las denominadas de campanillas o campanilleros ${ }^{6}$. En los primeros tiempos los rosarios contaban con un cantor que entonaba las coplas, al que acompañaban, amén de los devotos, un coro infantil para las avemarías y diversos instrumentos: violines, oboes, bajón, murta... Estos instrumentos, sobre todo los dos últimos, ya se constatan en 1691 en medio de cierta controversia, pues algunos concebían su inclusión como irreverente ${ }^{7}$. Pero lo más importante era la voz humana, creándose unos tonos propios en las distintas localidades e incluso dentro de las mismas.

"Desta forma van con mucho espacio, silencio, devoción y compostura, discurriendo por las calles que son necesarias para cantar los otros dos tercios del Rosario, en que se gastan dos horas y media, y a vezes tres, porque porque se van cantando con grandísimas pausas a canto llano, en tonos que cada parroquia ha inventado, o por mejor decir los ha dictado Dios, pues sobre ser gravisimos son tan devotos y sonoros al oído que parece que dentro de la comunidad, que parece que dentro de la comunidad van los coros angélicos, según la armonía causan y según mueven a lágrimas y ternura de devoción."

Las primeras coplas suelen ser de estrofas breves y muy sencillas y derivan de las saetas que los predicadores entonaban en las Misiones. De hecho, por ejemplo,

5 Cfr. Cartas de España, carta sexta, págs 170- 171, Madrid: Alianza, 1977.

6 Cfr. mi monografía El Rosario de la Aurora y sus Coplas. Tradición y religiosidad en Sevilla y su provincia, Sevilla: Publidisa, 2007.

7 El padre dominico Antonio de Cáceres, en un célebre sermón, se hace eco de estas críticas a los instrumentos, saliendo en defensa de ellos, afirmando que a algunos les mueve más a devoción el Rosario con los instrumentos "para que salgan con más dulzura las voces" y que en todo caso cualquier forma de rezar el Rosario es válida y agradable a Dios y, por tanto, todas ellas ganan las indulgencias concedidas. Cfr. Oración a las rogativas que por la sucesión deseada de nuestros... Monarcas hizo la Ilustre Parroquia del Sagrario...El Sermón tuvo lugar el 29 de abril de 1691. Impreso de la Biblioteca Universitaria de Sevilla 112/123. 
en Pedrera (Sevilla) se mantenía en la Novena de Ánimas la expresión de "Saetas del Rosario" relacionadas con las ánimas del purgatorio:

\author{
Por los cofrades difuntos/ de esta santa cofradia, / cristianos dadme \\ limosnal que os la premiará María \\ Por los hermanos difuntos/ piadosos, dadme limosnal porque se están \\ abrasandol en una oscura mazmorra.
}

A finales del siglo XVII se documenta ya la estrofa de siete versos con rima asonante, todos dodecasílabos menos el quinto, manifiestamente más corto, de cinco sílabas, que se repite y da paso a los dos últimos conclusivos, que por ejemplo, en Aracena ambos tres forman un estribillo común al total de las coplas. Fueron, sin duda, las más populares y de mayor repertorio musical. Modesto García Jiménez afirma que su estructura métrica es inusual y en apariencia sin antecedentes, pero si se dividen en hemistiquios los versos se halla una estrofa más común con versos de seis sílabas, frecuentes en los tradicionales villancicos, salvo que queda siempre el verso introductorio, que es más largo. ${ }^{8}$

En 1697 aparecen ya en Sevilla las primeras coplas con esta estrofa, como por ejemplo:?.

A la flor marchitada sin culpa/por vuestros pecados mortales llegad, / y veréis en la Cruz enclavadol a quien con su muerte la vida nos dalLlegad y miradl la amapola, la flor del almendrolla rosa, violeta y el lirio expirar."

Parece claro que, de alguna manera, sí hay un origen común, ya que los temas son muy similares así como determinados tenores que aparecen en localidades muy distantes entre sí. Esto no quiere decir que no existieran tradiciones de coplas precedentes como, por ejemplo, albadas, matinadas u otras canciones propias de los campos ajenas al Rosario de la Aurora y que ahora se adaptan. Tampoco puede decirse que la copla de siete versos es la única que se canta, pero sí es la de referencia para toda Espańa.

Otro problema, no menos importante, es que, al transmitirse básicamente de manera oral, muchas coplas son alteradas en su tenor, hasta el punto de que se hacen incomprensibles y sólo pueden entenderse recurriendo a algún repertorio de otras localidades más antiguo o menos alterado.

En impreso sin fecha, pero que cabe datar (por el impresor) en la tercera

8 Cfr. "Campanilleros y cantos o coplas de los rosarios de la aurora", Proyecto Andalucía. Antropología, Sevilla, Publicaciones Comunitarias, 2001, pp. 108-111.

9 Coplas divinas y espirituales, en alabança de María Santíssima Nuestra Señora, dirigidas a fervorizar la devoción de el Sanctíssimo Rosario, explicando los quinze misterios, en quinze flores, como verá el curioso lector. Sevilla, Lucas Martín de Hermosilla, impresor, 1697. 
década del XVIII, figura José Gómez Quintanilla, vecino de Écija (Sevilla) como compositor de unas $\operatorname{coplas}^{10}$ :

Sacudid la coyunda del sueñol que a vozes os Ilama el glorioso Guzmán/ a rezar el Rosario a la auroral de quien ha sido siempre siervo y capellán/pues vamos allál que daremos gran gusto a Domingol servicio a María, rabia a Satanás.

Otro importante autor de coplas de aurora fue Cristóbal de Aguilar (17331810), natural de Sevilla, aunque emigró pronto a Córdoba (Argentina), donde llegó a ejercer un alto cargo en el obispado. No se conoce la fecha en que fueron compuestas ni si el título genérico "Versos para recordar al Rosario de la Aurora" fue coetáneo o posterior a las coplas, aunque cabe inclinarse por lo segundo, ya que parece expresar una sentida nostalgia por una devoción que se hallaba en decadencia. Es decir, probablemente Aguilar compusiera las coplas antes de 1790, en que se integra la congregación de la aurora en la Cofradía del Rosario y el título en sus últimos años de vida, es decir, la segunda década del XIX, donde ciertamente hay una crisis generalizada de la religiosidad popular. Es necesario, pues, un estudio más exhaustivo para determinar el origen y difusión de estas composiciones. ${ }^{11}$

"El sonido de estas campanillas/ para el fiel devoto es despertador/ que, acordándole viene la aurora, / le exhorta a que alabe a la Madre de Dios/ Y el fino en su amorl por servir a su Reina y Señoralse levanta alegre a su devoción.

Salvando estos dos casos y algunos otros que pudieran aparecer (excepto el caso de las coplas contemporáneas que, aunque siguen el esquema tradicional e incluso se inspiran en antiguos tenores, pertenecen a autores populares conocidos a nivel local) la autoría de las coplas sigue siendo una cuestión pendiente. Probablemente las primeras procedieran de eclesiásticos regulares (frailes dominicos, capuchinos, jesuitas...) o seculares o laicos ilustrados afectos a las cofradías o congregaciones del Rosario.

Hay que distinguir entre las coplas propiamente del Rosario, que glosaban los Misterios o se referían a alguna festividad especial, y "las campanillas" que,

10 Coplas que cantan los muñidores del Venerable Orden Tercero de N.P. Santo Domingo de Guzmán de la ciudad de Écija, para llamar los hermanos a rezar el Rosario de la Aurora por las madrugadas. Compuestas por José Gómez Quintanilla, impresas por sucesores de Tomás López de Haro, Sevilla, sin año.

11 Cristóbal de AGUILAR, Obras. Madrid. Biblioteca de Autores Españoles, Madrid: Atlas, 1989-1990, tomos 299 y 300. Estudio preliminar de Antonio Serrano Redonnet y Daisy Ripodas Ardanaz y edición de Antonio Serrano Redonnet. 
como su propio nombre indica, eran tocadas por los "avisadores" para convocar a los vecinos al Santo Rosario y solicitar limosnas. De estos segundos derivan los muy numerosos coros de campanilleros que se crearon en todas las provincias andaluzas ya a fines del siglo XIX y primera mitad del XX.

Modesto García Jiménez distingue con acierto entre auroros, que conservan más el estilo antiguo de las coplas, con tonada más lenta, y utilizan muy pocos instrumentos (esquila, campanillas, guitarras, laudes...) y campanilleros, que entonan las coplas con tonadas más vivas y ligeras y utilizan muchos más instrumentos: panderetas, tambor, botellas de anís, triángulos e incluso trompetas (Aracena), saxofones, entre otros ${ }^{12}$. En Aznalcázar (Sevilla), por ejemplo, se distingue por parte del coro "Santiago Apóstol" entre tonos mayores (alegre, vivo), menores (lentos, "tristes") e incluso flamencos.

Aunque hay muchas clases de coplas, de estrofas diferentes, voy a establecer una clasificación en función de las tradicionales, es decir, de las de siete versos.

Estas coplas tienen distintas tonadas según la localidad o el coro que las interpreta, que puede utilizar tanto propias del lugar como de otras localidades. Dentro de ellas, como he anticipado, se distinguen tonos mayores, menores y flamencos. También es muy común la diferencia entre coplas modernas y antiguas, caracterizadas las primeras por textos más comunes con otras localidades y un ritmo más vivo, mientras que las segundas presentan tenores, que si no son originales o al menos enteramente, se refieren a coplas del XVIII o XIX y su ritmo es lento y peculiar. Es claro que muchas composiciones son cantadas en varias poblaciones, pues la dispersión fue muy generalizada y, en numerosas ocasiones, se ignora su origen.

Hoy en día esta clasificación, muchas veces, no es tenida en cuenta por los coros, que mezclan coplas de campanitas con las de misterio, las dedicadas a la Virgen e, incluso, las de ánimas, haciendo igualmente lo propio con las tonadas.

\subsection{Coplas de campanilleros, avisadores o despertadores}

"Las Campanitas", "Los Campanilleros" o "Auroros" marchaban con antelación por las calles que debía recorrer el Rosario haciendo sonar los instrumentos, posteriormente quizá entonando saetas o jaculatorias y, finalmente, cantando coplas. En algunos casos se contrataba un clarinero. La finalidad era anunciar a los vecinos el comienzo del Rosario, animarlos a participar y prevenirlos de las consecuencias nefastas para sus almas si no lo hacían. Por lo general son exclusivas del Rosario de la Aurora. Tienen diversas variedades y, aunque lo propio es entonarlas antes del Rosario, también en la actualidad lo hacen a lo largo del

12 Cfr. "Campanilleros y cantos o coplas de los rosarios de la aurora", op. cit, Sevilla, Publicaciones Comunitarias, 2001, pp. 108-111. 
cortejo, entremezcladas con otras propias de Misterios o en alabanza a la Virgen y todas con la misma tonada.

En la época moderna, estas coplas son cantadas exclusivamente por hombres, aunque en la actualidad los coros suelen ser mixtos.

Como ya se ha comentado, las coplas de campanitas tienen muy distintas tonadas, algunas muy lentas (que debieron ser las primitivas) y que recuerdan a los auroros y otras más animadas y ligeras, las propias de los campanilleros. Así se observa claramente en El Cerro del Andévalo, como se verá.

A partir del jerezano Manuel Torre, estas coplas se incorporan como un palo más del flamenco, siendo interpretadas por diversos solistas y grupos.

Las más antiguas conocidas son las ya mencionadas de los Muñidores de la Orden Tercera Dominica de Écija (Sevilla) que luego serán modelo para otras muchas localidades:

"De los ángeles oigo las vozes, / que alegres y ufanos cantan con placer, I porque dizen que sale la Auroral repartiendo flores al amanecer./Venid a coger/ de las fores fragantes, y hermosas/que siembra María contra Lucifer.

(José Gómez Quintanilla. Hacia 1735)

\subsection{Coplas de Misterios}

Desde finales del XVII se documentan ya coplas propias para cada Misterio, con breves estrofas y alto contenido teológico. Posteriormente se universaliza la estrofa de siete versos, como la de Campanillas. En la segunda mitad del XIX, al reestructurarse el Rosario público con las procesiones de la Aurora y el predominio femenino en estos, son las mujeres quienes entonan estas coplas, creándose modelos muy populares como los del canónigo Juan Francisco Muñoz y Pabón, que aún siguen vigentes en muchos pueblos de la provincia de Huelva. Se cantan normalmente en las iglesias y también en el Rosario público al enunciarse el título de cada Misterio.

\subsection{Coplas de ánimas}

Las coplas de Ánimas son composiciones sencillas, con la métrica tradicional de siete versos, y que evocan la triste suerte de las ánimas que piden oraciones y limosnas para ayudarlas a purificarse de sus pecados allá en el Purgatorio. Algunas están en tercera persona, pero muchas otorgan la palabra a las propias ánimas que, en primera persona, se dirigen lastimosamente a los vecinos para solicitar su sufragio y también para advertirles de la fragilidad humana ante la muerte y del riesgo de condenación eterna si no procuran, ya de vivos, salvar su alma de las acechanzas del pecado. 
Las Coplas de Ánimas son concebidas para cantarlas por las calles en noviembre por los Rosarios de prima noche y también para solicitar limosnas para las misas de sufragio, pero también en la iglesia previamente a la misa. Suelen cantarse con tonadas lentas y acompañadas con esquila o campanas.

Lamentablemente he localizado muy pocas en tierras onubenses hasta el presente.

\subsection{Coplas dedicadas a la Virgen}

Están dedicadas a las virtudes, privilegios y cualidades de la Virgen, referidas a la imagen titular de la hermandad o congregación, o a alguna festividad significativa (sobre todo la Inmaculada). Se utilizan también como coplas de llamadores o campanilleros. En la actualidad, también se cantan en las iglesias.

Hay otras coplas referidas a la Pasión de Cristo, santos, patronos de las poblaciones, sacerdotes, etc.

5. El Rosario en la provincia de Huelva. Generalidades. Escenarios REPRESENTATIVOS

En el estado actual de nuestros conocimientos, la devoción del Rosario en lo que hoy es la provincia de Huelva alcanza su primer gran momento de difusión en torno al último tercio del siglo XVI y primera mitad del XVII con las fundaciones de las cofradías por parte de la Orden de Predicadores en los tres conventos de la Orden: Aracena, Gibraleón y Lepe y sobre todo en las parroquias de las distintas poblaciones. Se corresponde, pues, con la etapa de la universalización del rezo y devoción.

Sin duda alguna, el segundo gran momento de la devoción del Rosario en las tierras onubenses fue el fenómeno de los Rosarios públicos o callejeros, que crearon un extraordinario dinamismo en el rezo, fundándose innumerables congregaciones dedicadas exclusivamente a la salida de los cortejos a prima noche y madrugada. Lo usual es que muchos tuviesen como sede capillas o ermitas, pues las parroquias no abrían sus puertas en la madrugada, hora en que salían los cortejos de la aurora. Las cofradías incorporaron a su instituto el Rosario público.

Elemento fundamental de estos Rosarios era el acompańamiento musical. Las coplas de campanilleros o auroros eran entonadas por los "avisadores" o "llamadores", que anunciaban la salida del cortejo. La copla usual era la de siete versos, que todavía hoy se conservan en muchas localidades.

En este artículo he seleccionado unas localidades que estimo representativas de la devoción del Rosario en la Huelva Moderna, especialmente en lo relativo a los rosarios de la aurora y sus coplas. Tras algunas noticias documentales, ofrezco una selección de las coplas de campanilleros o auroros, misterios, ánimas y marianas que se conservan en cada población. 
Sólo en el caso de Paymogo se conserva un repertorio original de la época que historiamos y que ciertamente es un referente fundamental. En las demás localidades, los repertorios que he podido consultar son contemporáneos y derivan en su gran mayoría de tradición oral autóctona, pero también provenientes de otras localidades. En todo caso, no se conocen los autores ni la fechas de composición, aunque sus tenores parecen datar de los siglos XVIII y XIX.

\section{ARACENA}

El Rosario público ha sido tradición devota en los domingos del mes de octubre en Aracena hasta la primera mitad del siglo XX, saliendo a la aurora el de hombres con sus coplas e instrumentos de campanilleros y por la tarde el de mujeres, entonando los Misterios en una estampa que evoca José Andrés Vázquez en un artículo sobre la figura carismática de la tercera dominica María de la Santísima Trinidad, a la que se atribuyen popularmente la autoría de las coplas, cuestión que hay que descartar, pues aún no había comenzado propiamente la tradición de los rosarios de la aurora. ${ }^{13}$

Actualmente los grupos de campanilleros cantan coplas en las madrugadas de los domingos de octubre, previas al Rosario de la Aurora y el último domingo del mes se celebra misa de campanilleros en la iglesia prioral del Castillo. Entre los instrumentos que utiliza el coro de campanilleros se encuentran desde los más antiguos como las esquilas, sonajas hechas con platillos metálicos dispuestos en dos tablas en forma de cruz, el cántaro y la alpargata, el triángulo, y la carrañaca. Durante el siglo XX se introdujeron novedades en torno a la pandereta, el saxofón, la bandurria y la guitarra para terminar con la trompeta y los timbales.

Ofrecemos una pequeña selección, en la que no nos consta la antigüedad ni la autoría. La primera copla es muy común en toda España y la novena es citada en el cancionero de Fray Diego de Valencina. ${ }^{14}$

13 Cfr. "La Venerable Madre Trinidad, una mística serrana", en Archivo Hispalense, 2a época, número 5, Sevilla: Diputación Provincial, 1944, pp1- 33. Sobre ella, vid. la biografía de Antonio de LOREA. La Venerable Madre Sor María de la Santísima Trinidad, religiosa de la tercera orden de Santo Domingo... prodigiosa en vida y admirable en virtudes, Madrid: Francisco Sanz, 1671. Su análisis y contextualización en J. Pérez-Embid y otros, Historia e historiadores sobre Huelva, Huelva, 1997 (p. 217-227: "La memoria local en la hagiografía "); del mismo autor, Aracena y su sierra. La formación histórica de una comunidad andaluza (siglos XIII-XVIII). Huelva, 1995, p. 253-375, especialmente p. 354-375: "visiones y escenas del Barroco en Aracena".

14 Cfr. Historia documentada de la saeta. Su origen y desarrollo. Los campanilleros y el rosario de la aurora con una esmerada colección de saetas populares y otra muy selecta del rosario de la aurora, Sevilla: Editorial Católica, 1947. El problema de este repertorio es que no cita la procedencia de las coplas. 
Coplas de campanilleros

(Todas las coplas conservadas tienen un estribillo común formado por los tres últimos versos):

\section{Cristianos venid, devotos llegadl a rezar el Rosario a Marial porque será mucha vuestra utilidad.}

1. El Rosario de la madrugadal es una cadena de mucho valor,lque por ella subimos al cielo/ a ver a María y a gozar de Dios. (Estribillo)

2. ¡Oh cristiano que quieto descansas/ en cama mullida con comodidad,/ luego despierta y atiendel a la voz que tu ángel diciéndote está. (Estribillo)

3. Lo que pierdes del dulce reposol la Virgen María te lo pagará./ Por un rato que pierdes de sueñol lograrás propicia a la Majestad (Estribillo)

4. El demonio en todo el infierno/ se turba y espanta cuando oye cantar/ el Rosario a la Reina divinal y deja a las almas bajo su piedad (Estribillo)

5. El cristiano que tema al infiernol empuñe el Rosario para pelearly acometa al demonio segurol de que con este arma le confundirá. (Estribillo)

6. Si contrito rezas el Rosario,/ aunque muchas culpas tengas que purgar,/ no te espantes porque cuanto debes/ el Santo Rosario lo puede pagar (Estribillo)

7. Al balcón de los cielos asomal la Virgen María, Reina celestial,/ y se alegran los ángeles todos/ al ver que el Rosario va a comenzar. (Estribillo)

8. Cuando el hombre comienza el Rosariol abre sus tesoros la divinidadl y reparte gracias singulares/ a los que contritos lo van a empezar (Estribillo)

9. De la iglesia de Santo Domingol sale un regimiento de mucho placerl y la Virgen va de Capitana, Ide cabo de escuadra Vicente Ferrer (Estribillo) (no 60 Valencina)

10. Corred, corred cristianos al Rosariol y mira que muchos a la iglesia van/ por rezar a la Virgen Marial y tú, perezoso, en la cama te estás (Estribillo)

11. Aún los niños y tiernas doncellas/ el sueño sacuden y saben llegarl entonando el Rosario a la Virgen/ y tú el blando lecho no quieres dejar (Estribillo)

12.jOh cristianos que tantos avisos/ recibis del cielo, alegres marchad/ a apuntaros a los fieles todos/ que el Santo Rosario van a comenzar (Estribillo)

13. Despertad, despertad almas todas/ y acudid contritas con much a humildad/ a rezar el Rosario a Marial estando seguro que os lo premiará ${ }^{15}$

\section{LA CORTE DE SANTA ANA}

En honor de su Patrona, la Virgen del Rosario, las mujeres de la aldea de La Corte de Santa Ana celebran una Novena de calle en su honor, reuniéndose junto a la iglesia a las cinco de la mañana para hacer una ronda por las calles entonando las antiguas coplas de la aurora en cada parada que hacen y que están establecidas

$15 \mathrm{Mi}$ agradecimiento a D. Diego Pérez Diajara por toda su colaboración para recopilar datos sobre el Rosario en Aracena. 
de antemano. Su origen parece ser que fue, como en el caso de Los Marines, la evitación del contagio de la epidemia. La Novena tiene lugar en los días anteriores a la festividad del Rosario, pero atendiendo a que son muchos los lugareños que han debido emigrar y vuelven en verano, se efectúa también durante el mes de agosto.

Las coplas responde a tenores ampliamente difundidos en otros muchos lugares, aunque la tonada sí parece autóctona. En las que ofrecemos, destaca en la primera el vocablo "resencio" propio de la sierra y que significa relente o rocío. Las mujeres han cobrado actualmente un protagonismo que debieron tener exclusivamente los hombres en la época moderna y entonan las coplas acompañándose exclusivamente de una campana o esquila. ${ }^{16}$

Coplas de campanillas o avisadores

El Rosario de por la mañanal es para los pobres que al campo se van,/ y los ricos se están en sus camas/ para que el resencio no les haga mall no les haga mall El Rosario de por la mañanal es para los pobres que al campo se van.

Coplas dedicadas a María

"Es María la caña del trigo,/ San José la espiga y el Niño la flor./ Y el Espiritu Santo es el grano/ que alli está encerrado por obra de Dios./ $Y$ con el alborl de los rayos primeros del díal nos da su sonrisa la Madre de Dios."

\section{EL CERRO DEL ANDÉVALO}

A comienzos del siglo XVIII encontramos ya mención del Rosario público que salía todas las noches de la parroquia. El mandato de Visita de 1725 hace mención al decaimiento de esta devoción y establece que se revitalice sacando una imagen de la Virgen en la comitiva, lo que podrá tener efecto cuando finalicen las obras de construcción de la capilla de la Trinidad, frente a la parroquia. ${ }^{17}$

Esta capilla de la Trinidad, frente a la parroquia, hubo de tener sin duda relación con las misiones capuchinas de Fray Feliciano de Sevilla, el gran apóstol de esta advocación, en los últimos años del siglo XVII y los primeros del XVIII. Probablemente se erigiera una congregación de la Trinidad y, como era usual en el capuchino, estableciera en ella el rezo del Santo Rosario por las calles.

16 Cfr. Las Novenas de La Corte de Santa Ana la Real, Santa Ana la Real, 2000. Vid. también un interesante trabajo de Ignacio Garzón González en que establece cuestiones métricas y comparaciones con coplas de otros lugares, no sólo de Huelva, sino de otras regiones españolas: http://gargonig.blogspot.com.es/2007/04/estudio-sobre-cantos-de-llamada-al.html (consultada $1-4-2015)$

17 Archivo General del Arzobispado de Sevilla, Visitas 05197. 1724-1727. 
Posteriormente habría sido renovada, fecha en la que hay que situar el dato anterior. No está claro que la Cofradía sea la encargada de este Rosario y sí quizá una congregación de devotos.

No hay más noticias sobre el particular hasta que en torno a 1764 varios vecinos de la localidad se refieren a esta tradición en una solicitud enviada al Arzobispado respecto a que se les permita abrir el templo parroquial antes del alba tal como era costumbre y además había aconsejado el célebre predicador Pedro de Calatayud en una Misión celebrada en la villa en 1758: [...] "Decimos que desde tiempo inmemorial a esta parte ha habido en dicha villa la devoción de llamar por las calles al Santísimo Rosario al tiempo del alba, y después de juntos los devotos se ha cantado el rosario por las calles y en el interim en su iglesia parroquial, que a este fin se abre una de sus puertas, concurren muchos devotos y devotas, y se ejercitan dentro de ella en la Via Sacra y otros santos ejercicios hasta que llegan los devotos del rosario por las calles, y luego se les dice misa por un eclesiástico...concluyéndose a la hora de las avemarias... siguiéndose el que muchos asistan a él, oigan misa y salgan temprano a sus trabajos y el que otros pobres que no tienen vestidos decentes para oirla más alto el día concurren a esta hora [...]"18

Todo parece indicar que se refiere a la procesión del Rosario de madrugada que solía salir los domingos y festivos. No sabemos si continuaría el de prima noche a diario. Sin duda, la Misión del padre Calatayud fomentó este cortejo de madrugada.

Se conserva un repertorio de coplas de la aurora, muchas de las cuales se remontan al siglo XVIII y XIX. En la actualidad un grupo de jóvenes de la Hermandad de la Virgen del Mayor Dolor las cantan por las calles en dos ocasiones: la madrugada del domingo más cercano a la festividad de la Virgen del Rosario (7 de octubre) y el último sábado de octubre. En la primera, a partir de las tres de la mañana salen por las calles del pueblo los denominados "Llamadores" que anuncian la salida del Rosario combinando coplas antiguas del XVIII y XIX con otras de comienzos del siglo XX como las de "Viva María/ Viva el Rosario/ Viva Santo Domingo/que lo ha fundado". El acompañamiento musical es propio de la esquila y los campanilleros: esquila, guitarras, triángulos, panderetas, sonajas y botellas de anís. A las 7 de la mañana sale el Rosario de la parroquia con la cruz, faroles, el estandarte de la Hermandad y una imagen de la Virgen de Fátima. Junto a las avemarías, se entonan las coplas de Misterio, con letra de Muñoz y Pabón. A finales de octubre se sale de noche con el Rosario desde la parroquia hasta la ermita de la Virgen del Mayor Dolor, junto al cementerio y tiene un carácter o tipología de ánimas, cantándose las coplas antiguas.

18 José Rico Romero. Iglesia parroquial Nuestra Señora de Gracia (Aproximación histórica), El Cerro del Andévalo, 1999, pp. 39-41. 
El hecho de haberse conservado la tradición de los Rosarios se debe, por un lado, a una devoción nunca interrumpida que se ha legado de padres a hijos, pero también a las Misiones de capuchinos y jesuitas en la época moderna y de maristas y padres blancos en la contemporánea. En los años 40 del pasado siglo se creó una dinámica devocional ciertamente interesante en la festividad de octubre, saliendo a lo largo de la jornada tres comitivas: a la aurora, por mujeres, al mediodía por hombres y finalmente por la tarde ya todo el pueblo.

El análisis de las coplas nos revelan que se trata de letras muy populares, comunes a otros puntos de Andalucía y Espańa, pero también que se entremezclan tenores de una con los de otra u otras, alargando las siete estrofas hasta diez en diversas ocasiones. Hay dos tonadas, la que se denomina antigua que se refiere a un repertorio de coplas y las nuevas, al actual y más cantado. Los tenores son de muy diversa temática: escenas de la Pasión, santos... La primera que ofrecemos, incompleta (se repiten los dos últimos versos como estribillo) es muy singular. Ofrecemos también otras dos coplas muy raras, quizá autóctonas, sobre la Pasión $\mathrm{y}$ dos santos ${ }^{19}$

Coplas de llamadores

El demonio patita de palolen un carapullo se quiso meter,/se quiso meter (2)/Y le dijo la Virgen Maria:/¿dónde vas Demonio, si no has de caber?

Coplas de la Pasión

A las cinco ; Quépena tan grande!l recibió San Pedro en su corazón/ cuando el gallo le cantó tres veces/por haber negado a su Creador/Y se arrepintió (bis)/ De rodillas se puso postradol llorando sus culpas...y alcanzó el perdón.

\section{Coplas de santos}

San Andrés, que pecando estabal con su hermano Pedro. Jesús que llegól con las redes para pescar almas/diciendo: hijo mío, vámonos los dos/San Pedro quedó (bis)/ como piedra, columna encendidal San Andrés, por Cristo, se martirizó.

En la Sierra de Aracena existe la tradición de las coplas de aurora en otras poblaciones como Galaroza con el coro de campanilleros de la Virgen del Carmen.

19 Mi agradecimiento a D. Domingo Tejero, D. José Rico y a la Hermandad de la Virgen del Mayor Dolor. 


\section{PAYMOGO}

La tradición de los Rosarios de la aurora y sus coplas en Paymogo parecen remontarse a la primera del siglo XIX y quizá algunas a la segunda del XVIII. Apenas he encontrado datos documentales sobre el particular, pero se conserva un interesantísimo repertorio de coplas de esta época, lo que constituye un preciado tesoro para conocer de primera mano las composiciones más antiguas que se cantaban en las tierras de Huelva y un referente imprescindible para el resto de localidades, cuyos repertorios de coplas provienen en su gran mayoría de tradición oral y aparecen mezcladas composiciones de diversas épocas.

El documento consta de dos cuadernos, con tamaño de media cuartilla. El primero tiene once hojas y el segundo diez, con distinta caligrafía cada uno. El primero se titula "Coplas para llamar al Rosario el día de la Pura y Limpia Concepción" con dieciocho coplas (no todas con la métrica de siete versos) y el segundo "Coplas de llamar al Rosario" con treinta que sí responde a las composiciones tradicionales. Para Manuel Peña Díaz, el primero sería anterior al segundo, pero ambos del siglo XVIII, estableciendo la hipótesis de que los tenores pudieran proceder de la villa de Huelva por la mención que se hace a la parroquia de San Pedro. ${ }^{20}$ Sin embargo, también se menciona en otra copla a la ermita de San Sebastián de Paymogo, desde donde efectivamente salían los cortejos de la aurora en el siglo XVIII.

En fechas recientes ha habido un importante movimiento revitalizador de la Cofradía del Rosario de la localidad, así como del Rosario de la Aurora y sus coplas.

Coplas de auroros

1. En el nombre de Dios poderosol la Aurora Divina la vengo a alabarl no conforme la Virgen merece,/ sino como pueda mi lengua explicar/ Bien conozco yal que tu much a devoción me muevel y tus alabanzas salgo a publicar (no 102 de Valencina las cuatro primeras estrofas)

2. Madre mía Virgen de la Auroral dadme vuestra gracia para principiarl que os lo pido contrito y humildel postrado ante el trono de vuestra piedadl Me lo habéis de darl Madre mía Reina de los cielos/ porque os lo pido con grande humildad

3. Alabar a la Aurora Marial intentan acordes mi asento y mi vozl publicando mi canto y mi aplausol con eco sonoro del ave mejor/ Tener atención/ Que aunque rudos sean mis conceptos/ Rendido el afecto y mi corazón

4. Soberana y divina princesal Que ya he dado vuelta por todo el lugar,/ dando

20 Agradezco a D. Manuel Peña Díaz el envío de fotografías digitales de las páginas de este libro, sobre el que realizó un breve artículo: "Un manuscrito de coplas" en la revista Rosario, editada por la hermandad de la localidad, Paymogo, 2014, pp. 46-48. 
voces llamando a los hombres/ que al santo rosario vengan a rezarl Virgen singular/ Si mis voces no son suficientes/ llamad vos Señora, llamad, Ilamad

5. En tu puerta está la campanillal con lengua de plata, labios de marfill Levantad $y$ venid al rosario/ Sabrás en la hora que te has de morir/ Y vuelvo a inferir/ El Rosario es la escala devotol por donde podemos al cielo subir

6. Qué alegría, que gozo tan grandel no tendrán los cielos "al ver cantar"/ Que los ángeles "paran mi coro"/ porque nuestras voces se oigan allál Vamos a alabarl A Maria que es del cielo y tierral La fuente de gracia, nuestra eterna paz

7. Soberana y divina Princesal Llena tengo el alma de gusto y placer/ De alegría que ya tus devotos/ Van a tomar armas contra Lucifer/ Pues es para él/ El Rosario de esta grande Princesal El mayor tormento y más amarga hiel

8. Al entrar el rosario en la ermital la Virgen María volvió el rostro atrás/ para dar los agradecimientos/ a las buenas almas que al rosario van./ -vamos a rezar-l el sagrado rosario a Marial a la santa ermita de san Sebastián. (no 17 de Valencina: sólo cierta similitud)

9. La corona se quitó la Virgen/ a su Hijo en la mano se la presentól Y le dice yo ya no soy Reinal si Tú no suspendes tan fuerte vigorl Dice: Madre mía de mi corazón./ El perdón lo tenéis alcanzado/ si al santo rosario van con devoción

10. Ya con estas mis coplas se acaban/ porque ya en mi lengua no hay declaración/ La campana que traigo en las manos/ Yo y mis compañeros pedimos perdón/ Tened atención/ La campana que traigo es Marial y por compañero el Hijo de Dios

Coplas de Misterios

Fueron tres los que te saludaron/Aurora Divina en tu Anunciación/ San Gabriel fue el primero que dijo/ Ave Gracia Plena contigo el Señorl $Y$ le respondiól Dime Ángel como ha de ser esol Si en mi es imposible obra de varón

Coplas dedicadas a la Virgen

1. Alabar a esta Reina divinal imitando al ángel señor San Gabriell a decir Dios te salve Marial Llena de gracia Dios contigo es/ Y puedes creer/ Que no hay hora que alabe a Marial para saludarle al amanecer

2. El glorioso Ildefonso nos dice:/ nadie sin María se puede salvar/ Y tú juzga que con tu perezal ganarás la gloria por eternidad/ Pues no juzgue tall Que en los siete vicios capitales/ está la pereza por culpa mortal

3. Alabemos todos a esta Reinal imitando al ángel señor San Gabriell Y decir: Dios te salve Marial Llena eres de gracia. Dios contigo es/ Y debe creer/ Que no hay hora que alabe a Marial para saludarle a el amanecer

4. Serenisima Imperial Auroral Divina Maria de la Concepción/ A tus plantas, Señora, humillado/ por víctima ofrezco mi fiel corazón/ Con tan fino amor/ 
Que perdiera Señora mil vidas/ por defender sólo tu puro candor

5. Soberana y divina Princesal Llena tengo el alma de gusto y placer/ De alegría que ya tus devotos/ van a tomar armas contra Lucifer/ Pues es para éll El Rosario de esta grande Princesal el mayor tormento y más amarga hiel

6. Quien rezare siquiera una Salvel aquesta Señora con tierno fervor/ Ganarás muchos dones de gracial con méritos grandes de su devoción./ Tened atención,/ Que Maria procura librarnos/ del torpe designio de la perdición

7. A los ocho (días) del mes de septiembrel celebra la Iglesia la Natividad.I Alabemos todos a esta Reinal Bendita entre todas las hijas de Adán./ Vamos a alabarl a la Reina que es de cielo y tierra, I la Fuente de Gracias, nuestra eterna paz.

8. Es María la mujer más pural que en el mundo pudo parir y criarl azucenas, jazmines, violetas, / la flor del romero y blanco azahar./ Y esto es tan verdadl Como Cristo murió por nosotros/Y la Virgen Madre le vido expirar

9. Es María divino portento/ que deja confusa la humana razón,/ porque siendo de Dios Hija tierna, / hacer también vino la Madre de Dios./ -tened atencion-I que es Maria la flor de la gracial y Dios es el fruto que trajo esta flor.

10. Eres palma alta y encumbradal de la hermosa torre del gran rey David.I eres hija del eterno Padrel y madre del verbo, pues encarnó en ti.l -del gran Salomón-l eres hija del eterno Padrel y madre del Verbo pues en ti encarnó.

11. Entre todas las flores del campo/ se lleva la palma, la de Jericó, / es María la blanca paloma, / su nombre bendito de la encarnación./ Tened atención/ que es Maria la flor de la gracia, / su nombre bendito de la Concepción.

12. Bajó el Verbo y encarnó en Marial Como cuando un vidrio lo penetra el soll Se juntaron dos naturalezas/Divina y humana en un solo Dios/Tened atención/ $Y$ esto es tan verdad como Cristo murió en un maderol Para redimirnos la culpa de Adán

13.;Dios te salve llena eres de gracia!,/ el ángel te dijo: contigo el Señor,/ porque fuiste la Reina escogidal entre las mujeres por Madre de Dios./ -tened atención-I que de toda la naturaleza, / ventura y aplausos, corona y honor.

14. Es Maria la luz verdaderal por donde los hombres puedan alcanzarl el perdón aunque tengan más culpas/ que hojas en los montes y arena del mar./ (-y esto es tan verdad-como Cristo murió en el maderol para redimirnos las culpas del mal.) * no figura lo que está entre paréntesis

15. Quien quisiere vivir venturoso,/ saliendo triunfante de la tentación,/ traiga siempre a María en sus labios/Saldrá de los vicios feliz triunfador./ Tened atención/ Que Maria la carne administral adonde se abrase nuestra Redención

16. Quien quisiere ver un gran prodigiol De una vara seca verla enflorecerl En la iglesia mayor de San Pedro (a lápiz "Paymogo")/ La tiene en la mano el señor San Josél Vamos a ofrecerl a esta Reina que es del cielo y tierral Hallaremos en ella todo nuestro bien 
17. Es María la nave preciosa/ San José la vela y el Niño y el timón/y los remos son las buenas almas/ que van al Rosario con gran devoción/ Todos a una voz/ El Rosario cantemos gustosos/ ángeles seremos en la imitación

18. Miró Juan a esta Reina divinal y toda vestida de rayo de soll coronada de estrellas su frentel pues también la luna los pies le calzól Tened atención/ Que a la voz virginal de Marial a Juan le ha causado recreo mayor

19. Visitando Isabel su pariental recibió el Bautista de Cristo un favor/ Por el cual en el vientre maternol fue santificado el gran precursor/ Tened atención/ Que al impulso del pie de Marial rindió la cabeza el fiero dragón.

20. Es María la blanca azucenal que entre las espinas el hombre naciól sin tocarle la mancha heredadal del vil apetito que Eva nos diol Tened atención/ Que enamora el Espiritu Santol al ver cum esposa tan limpio candor

21. Es Maria la rosa fragantel que al cielo recrea su mistico olorl y deleita su vista apaciblel pensiles amenos allá en Jericó (copla incompleta)

\section{ZALAMEA LA REAL}

Pastor Cornejo ha investigado el fenómeno rosariano en Zalamea la Real, especialmente lo referido a las coplas de aurora, que goza de notable tradición.

No se ha encontrado documentación sobre la misma hasta el siglo XVIII en que consta la existencia de una congregación dedicada al rezo público del Santo Rosario por las madrugadas, creándose en 15 de febrero de 1719 un interesante "Patronato del Rosario por la calle" por legado testamentario del sochantre Juan Moreno de los Reyes sobre diversos bienes de su propiedad, expresando su intención: "por cuanto tengo reconocido y es conforme a mi devoción la grande utilidad espiritual que se sigue por la permanencia de la devoción frecuente de rezar el Rosario de Ma Stma y con especialidad en público y por las calles para excitar más a la devoción y beneficio de las ánimas del Purgatorio ha sido y es muy conveniente se diga misa inmediatamente que el Rosario se restituye a la Iglesia por la madrugada, pues con este fervor y estímulo concurre lo más del pueblo de uno y otro sexo uniendo las dos devociones de Rosario y Misa..." Concretamente son diez las propiedades sobre las que crea el patrimonio a fin de que sus rentas se inviertan en limosnas de misas a celebrar tras la recogida del Rosario de Madrugada o misas de alba.

Hoy en día se mantiene la tradición del Rosario de la Aurora y sus coplas gracias a los propios vecinos y la asociación "Amigos del Rosario" que componen un coro excepcional, exclusivo de hombres, por la calidad de sus composiciones. La tonada es lenta, antigua, con muchos matices en las voces, acompañadas de la esquila, violines y guitarras. 
Coplas de auroros

1. Con esta copla abro el recorrido/ que ofrezco cantando por mi salvación,/ para el día que deje esta vidal comparta los frutos de la Redención./ Bendícenos, bendicenos/ y el camino que abrimos cantandol que llene de gozo tu gran corazón.

2. Perdonad, Virgen del Rosario,/ si ya a estas horas no entona mi voz,/ pero es largo el camino que he andado/ llenando la noche con tu devoción./ Recoge mi voz, recoge mi vozl y el eco que deje al marcharmel que sea la simiente de tu inmenso amor

3. Alegraos Divina Señora,/ que ya he dado vueltas por todo el lugar, / con la esquila llamando a los hombres/ que el Santo Rosario vengan a cantar./ Virgen singular, Virgen singular./ Si mis voces no son suficientes, / llamad Vos, Señora, llamad vos, Señora

4. El devoto que más madrugarel a coger las rosas del santo rosal,/ hallará una corona de gloria, / la Virgen María labrándola está./ Salid sin tardar, salid sin tardarl que impaciente os espera la Aurora, / gustosa de oiros sus glorias cantar/

5. ¿Qué disculpa pondrá el perezosol en aquel divino tribunal de Dios, / cuando diga el demonio: / este alma por jamás y nunca un rosario rezó?/ Vamos con fervor, vamos con fervorl a rezar el Rosario a Marial y ángeles seremos en su imitación.

Coplas de ánimas

De las ánimas oigo las voces/ con tristes lamentos decian asi:/ no hay un alma que de mi se acuerde, / ni las que heredaron el caudal de mi.l Podéis advertir, podéis advertirl que es basura cuanto poseéis,/ aqui si podéis caudal adquirir.

Coplas dedicadas a la Virgen

1. Es María la espiga de trigo,/ San José la caña y el niño la flor, / el Espiritu Santo es el grano / que está alli encerrado por obra de Dios./ ;Oh! Divino Sol, ¡oh! Divino Sol./ Dadnos gracias con que merezcamos/ gozar de los frutos de Vuestra Pasión.

2. La Pastora Divina que vuelal del Cielo supremo a la cumbre Mayor, inclinando sus ojos a la tierral mirando el rebaño de su posesión./ Todos a una voz, todos a una voz./ Te pedimos Dolorosa Madrel una buena muerte para ver a Dios.

3. Desde el Cielo descendió Marial traía un Rosario con gran majestad,/ se lo puso a Domingo en la manol que lo repartiera por la cristiandad.I Ángeles y hombres la vieron bajar./ Por la cumbre de un pilar hermoso/ con una luz bella dando claridad. 


\section{EL VILLAR}

Hay un documento fechado 4 de Octubre de 1.796 y escrito de puño y letra por Bartolomé Díaz Aldar, párroco de El Villar, en el que insta a los parroquianos a seguir la tradición y asistir al Santo Rosario que se ha de cantar por la mañana al alba recorriendo las calles de la aldea tal como lo hacía el sacristán Lázaro Peña, administrador de la Cofradía del Rosario. Así mismo este cura hace un breve comentario del origen de este cántico que llegó a El Villar siglos antes por un cura castellano que no cita el nombre, y que dicho cántico por ser tan bello y popular, desde allí se irradió a otras poblaciones del entorno de la aldea. ${ }^{21}$

La tradición popular afirma que la tradición de las coplas de la aurora en la comarca minera tiene su origen en El Villar y desde allí pasó a Zalamea o Riotinto. De hecho, el tenor de muchas coplas es similar.

Según Emilio Gómez Calvo, la tonada de las coplas es de un compás de 4/4 andante y se cantan a dos voces. La segunda voz es al tercer grado, destacándose algo más la primera. El acompańamiento musical se compone de guitarras, bandurrias, violines y, por supuesto, la esquila.

En la selección siguiente las coplas son de cuatro estrofas. Pienso que les falta el estribillo.

Coplas de auroros

1. Entonando la esquila en la mano/se abuyenta el demonio al verme venirl porque vengo llamando a los hombres/ que al Santo Rosario vengan a asistir.

2. Es Maria bella jardineral que reparte flores al amanecerl El devoto que se levantasel de esta rosa hermosa logrará escoger/ Vamos a escoger/ de esta rosa fragante y hermosal que María tiene contra Lucifer.

Otra localidad muy importante como escenario de las coplas de aurora es Minas de Riotinto. La tradición de la "esquila" parece derivar de las dos anteriores poblaciones, pero ha adquirido- ya en la época contemporánea- una extraordinaria difusión a nivel nacional e internacional. Por adquirir su auténtica fisonomía ya en el siglo XIX no aparece aquí referida con la atención que, sin duda, merece.

21 Emilio Gómez Calvo. Apuntes de El Villar, Huelva, 2003. Puede consultarse en el blog "La otra mirada" http://zalamealareal.blogspot.com.es/2008/10/el-rosario-de-por-la-maana.html (consultado 31-3-2015) 


\section{BOLLULLOS PAR DEL CONDADO}

En esta localidad se conserva la más importante recopilación de coplas de aurora (262), fruto de un encomiable trabajo de búsqueda en la tradición oral. En él aparecen coplas antiguas con otras contemporáneas. ${ }^{22}$

Coplas de campanillas (los números entre paréntesis corresponden al del cancionero consultado, propiedad de la Hermandad del Rosario de la localidad)

1. En el nombre de Dios poderoso/ empieza mi lengua, Reina celestial,/a cantar la grandeza y triunfol del Santo Rosario para ti alabar/ Mi voz alentad/ Conque pueda mi eco humildelal hombre alegrarlo, al diablo aterrar.

2. Cuando tocan al Santo Rosario/ acuden los fieles con gran devoción/ Los angélicos coros se postran/ y juntan sus voces con nuestra oración/ Vamos con fervor/ a decirte, Reina Soberana,/de tu mano pende nuestra Salvación (26)

3. El demonio te dice al oído:/ deja hoy el Rosario que mañana irás/ No te engañes. Levántate aprisal que acaso mañana la muerte vendrál Feliz vivirásl si al Rosario no dejas un díal la Virgen María tu amparo será (27)

4. Oh cristiano que estás en la cama,/ el sueño sacude. No da más dormir/ Pues te llama la Virgen Marial y su voz bendita la hemos de oirl Haz pues por venirl que al devoto del Santo Rosariol nuestra buena Madre consuela al morir (28) (no 181 de Valencina)

5. Ya sabéis, Soberana Princesa,/ como hemos cantado por todo el lugar/ dando voces llamando a los fieles/ para que al Rosario vengan a rezarl Porque es la verdadl Que desea con toda su almal ver a sus hijos al pie del altar (30) (no 240 de Valencina)

6. Los hermanos de las campanillas/ por calles y plazas salen a pedir./ No le temen ni al frío ni al agual ni a las malas noches que suelen venirl Pues se ha de advertirl que la vida de Cristo nos dicel que todos debemos orar y sufrir (31) (no 174 de Valencina)

7. Al entrar el Rosario en la iglesial la Virgen María vuelve el rostro atrás/ para darle el agradecimientol a todo cristiano que al Rosario val En particularl al devoto que deja la camal siempre que lo llama por la madrugá (33) (no 17 de Valencina)

22 Mi agradecimiento a D. Juan Ignacio Pérez Díaz y a la Humilde, Fervorosa e Ilustre Hermandad y Cofradía de Nazarenos de la Santa Cruz en Jerusalén, Nuestro Padre Jesús Cautivo, Nuestra Señora de la Victoria, María Santísima del Rosario, San Juan Evangelista y Santo Domingo de Guzmán de esta localidad, por facilitarme el acceso al repertorio de coplas de la aurora. 
Coplas de Misterios

1. En el huerto Jesús Nazareno,/ puesto de rodillas a su Padre oról con angustia y dolores tan grandes/ que sudando sangre la tierra regól Aceptad Señorl ese cáliz que ofrece el ángell porque de él depende nuestra Salvación (83)

2. Jesucristo atado a una columnal De azote le dieron más de cinco mill y sus carnes reventar querían/Sus huesos por partes quería salir/ Ay Dios, quésufrirl ¿Qué delito habrás cometidol para que a ese hombre le trate asi? (211)

Coplas de ánimas

Una madre le grita a su hijal desde el Purgatorio sin poder salir:/ hija mia, qué grandes dolores/ pasé en estos días cuidando de til Y ahora iay de míll No te acuerdas de tu pobre madrel Ni un avemaria has rezado por mi (227)

Coplas dedicadas a la Virgen

1. En el nombre de Dios uno y trinol la Aurora bendita la voy a alabarl no conforme la Virgen merece, / sino como pueda mi lengua explicar/ Porque para alabarl de su honor y su gran excelencial no es nada la ciencia de un Santo Tomás (47)

2. Es María la encarnada rosal que tiene el Eterno en su lindo rosall Por ser esta la rosa más pural la nombró por Madre del Rey Celestiall Hay más que explicar/ Que en el claustro puro de la Virgen/ entró un sol divino como en un cristal (48)

3. Si por Eva perdimos la gracial por Ti la ganamos, Reina Celestial,/ Porque fuiste la segunda Eval que al mundo trajo nuestra libertad/Y por tu humildad/ mereciste que un Dios verdaderol te llamara Madre con amor filial (59). 
